Rev. Saúde públ., S. Paulo

7: 21-28, 1973.

\title{
ASPECTOS EPIDEMIOLÓGICOS DA ESQUISTOSSOMOSE MANSÓNICA NA REGIÃO DA REPRESA DE AMERICANA, ESTADO DE SÃO PAULO, BRASIL
}

\author{
Luiz A. MAGALHÃES ** \\ Luiz Candido de Souza DIAS ** \\ José Toledo PIZA *** \\ Luiz TAKAKU *** \\ Alvaro A. PEREIRA
}

RSPU-B /157

Magalhães, L. A. et al. - Aspectos epidemiológicos da esquistossomose mansónica na região da Represa de Americana, Estado de São Paulo, Brasil. Rev. Saúde públ., S. Paulo, 7: 21-28, 1973.

Resumo: Apos conhecimento de casos humanos de esquistossomose mansônica supostamente autoctones da Represa de Americana (São Paulo, Brasil) procedeu-se ao estudo epidemiológico da região. Foram constatados seis focos localizados junto à Represa. Foram encontradas as seguintes espécies de moluscos: Biomphalaria tenagophila; B. straminea; B. peregrina; Drepanotrema cimex; D. lucidum; Lymnaeidae; Ancylidae e Physidae. Exemplares de Biomphalaria tenagophila coletados nos focos apresentaram inaices de infecção para cercárias de $\mathrm{S}$. mansoni que variaram de 0,9 a $45 \%$. Mus musculus albinos foram infectados com cercárias no laboratório e nos focos, sendo reproduzido o ciclo do $\mathrm{S}$. mansoni em ambas as condições. Foram registrados 82 casos humanos autoctones de esquistossomose mansónica, na região da Represa de Americana.

UnItermos: Esquistossomose mansónica*; Epidemiologia*; Molus$\cos ^{*}$; Infeç̧ão humana.

\section{N T RODU ÇAO}

Em meados de 1970, chegou ao nosso conhecimento a existência de casos humanos de esquistossomose, provavelmente autóctones da Represa de Americana.
A região suspeita localizava-se numa enseada da Represa de Americana em local conhecido como "João Aranha", no Município de Paulínia.

Examinados cerca de 500 exemplares

* Trabalho realizado com o auxilio do Conselho Nacional de Pesquisas e graças à colaboracão entre a Universidade Estadual de Campinas e a Campanha de Combate à Esquistossomose.

* Do Instituto de Biologia da Universidade Estadual de Campinas - Caixa Postal 1170 Campinas, SP - Brasil.

** Campanha de Combate a Esquitstossomose - Rua Atibaia, 267 - Săo Paulo, SP. - Brasil.

**** Distrito Sanitário de Campinas - Rua Boa Ventura do Amaral, 782 - Campinas, SP. Brasil. 
MAGALHAES, L. A. et al. - Aspectos epidemiologicos da esquistossomose mansônica na regiæ̋o da Represa de Americana, Estado de São Paulo, Brasil. Rev. Saúde públ., S. Paulo, 7:21-28, 1973.

de Biomphalaria tenagophila capturados no local, todos mostraram-se negativos para cercárias de Schistosoma mansoni. As capturas de planorbideos estenderamse por um periodo de três meses. Na mesma ocasião, foram expostos camun. dongos de laboratório, às águas da represa. Após 60 dias, os roedores foram sacrificados verificando-se não estarem infectados pelo $S$. mansoni.

Um ano após surgiram novos casos de esquistossomose, provavelmente autóctones de outra enseada da represa localizada junto à fazenda Saltinho, no Município de Americana.

\section{MATERIAL E METODOS}

A classificação dos planorbídeos foi feita de acordo com trabalhos de PARAense 7, 8 (1961, 1963), Paraense \& DeslanDes 9, 10, $11(1956,1958)$ e pela paho 7 . Para determinação dos índices de infecção os moluscos eram submetidos ao calor e à luz emanada de uma lâmpada elétrica de $60 \mathrm{~W}$ colocada a $40 \mathrm{~cm}$ dos caramujos (Pellegrino \& Macedo 12, 1955).

Os moluscos eram também esmagados entre lâminas de vidro e observados à lupa estereoscópica.

Com as cercárias de $S$. mansoni obtidas foram infectados por imersão, Mus musculus albinos, durante duas horas, recebendo cada roedor aproximadamente 100 cercárias.

Após 60 dias os camundongos sobreviventes foram sacrificados, sendo extraídos vermes por perfusão dos vasos mesentéricos e hepáticos (Yolles et al.15 1947; Brener 1, 1962) e por esmagamento do fígado entre lâminas de vidro (STANDEN 14, 1953; Hill ${ }^{4}, 1956$ ).

Do fígado dos camundongos infectados foram obtidos miracídios, após liquidificação do órgão, sedimentação do liquidificado e exposição à luz do sedimento.
Utilizando gaiolas flutuantes, foram expostos Mus musculus às águas da represa e seus afluentes. As gaiolas eram expostas às 14 horas, em dias ensolarados, ficando em contato com as águas por duas horas.

O diagnóstico dos doentes autóctones foi feito em sua grande maioria pelo achado de ovos de $S$. mansoni no exame de fezes (métodos de Hoffman e Kato) realizados pelo Instituto Adolfo Lutz de Campinas e pelo Setor de Parasitologia da Universidade Estadual de Campinas. Poucos casos foram diagnosticados pela reação intradérmica. $O$ antígeno empregado foi o do Instituto de Biologia da Faculdade de Filosofia da Universidade Federal de Minas Gerais. A leitura foi feita usando-se placa de celuloide (PELLEgRINo \& MACEDO 13, 1956).

\section{RESULTADOS}

\subsection{Levantamento malacológico}

Encontramos planorbídeos em toda represa constatando-se maior densidade de moluscos nas enseadas onde as águas apresentam menor movimentação e maior concentração de aguapés (Eichornia $\mathrm{sp}$ ).

Foram encontradas as seguintes espécies de moluscos: Biomphalaria tenagophila, $B$. straminea, $B$. peregrina, Drepanotrema cimex, D. lucidum, Ancylidae, Lymnaeidae e Physidae.

Os exemplares de $B$. straminea foram coletados em tanques de piscicultura da Companhia Paulista de Força e Luz e em um canal afluente da represa. $O$ encontro de $B$. straminea neste local havia sido referido por CoRkÊA et al. 2 (1970) e introduzidos por exemplares de peixes vindos do Nordeste.

Pesquisamos cercárias em cerca de 10.000 exemplares de $B$. tenagophila. 
MAGALFÃES, L. A. et al. - Aspectos epidemiológicos da esquistossomose mansônica na região da Represa de Americana, Estado de São Paulo, Brasil. Rev. Saúde públ., S. Paulo, 7:21-28, 1973.

No estudo da região, verificamos a existência de seis focos de S. mansoni localizados em uma enseada, uma lagoa, córregos afluentes da represa e em uma várzea (vide mapa). Os índices de infecção por amostra são os constantes da Tabela 1.

TABELA 1

fndices de infecção por S. mansoni encontrados em crladouros de B. tenagophila na região da Represa de Americana

\begin{tabular}{ll|c|c|c|c}
\hline Data & \multicolumn{1}{c}{$\begin{array}{c}\text { Localização } \\
\text { do } \\
\text { criadouro }\end{array}$} & $\begin{array}{c}\text { Tipo } \\
\text { de } \\
\text { criadouro }\end{array}$ & $\begin{array}{c}\text { Número } \\
\text { de } \\
\text { examinados }\end{array}$ & $\begin{array}{c}\text { Número } \\
\text { de } \\
\text { infectados }\end{array}$ & $\begin{array}{c}\text { Percentual } \\
\text { de } \\
\text { infectados }\end{array}$ \\
\hline $12 / 11 / 71$ & Saltinho & Enseada & 74 & 2 & 2,7 \\
$12 / 11 / 71$ & Saltinho & Enseada & 42 & 5 & 12,0 \\
$12 / 11 / 71$ & Saltinho & Enseada & 75 & 3 & 4,0 \\
$12 / 11 / 71$ & Saltinho & Enseada & 22 & 10 & 45,0 \\
$19 / 11 / 71$ & Saltinho & Enseada & 40 & 6 & 15,0 \\
$23 / 11 / 71$ & Saltinho & Enseada & 28 & 11 & 41,0 \\
$23 / 11 / 71$ & Saltinho & Enseada & 47 & 7 & 15,0 \\
$18 / 12 / 71$ & Foguete & Córrego & 85 & 1 & 1,2 \\
$18 / 12 / 71$ & Foguete & Córrego & 162 & 6 & 3,7 \\
$18 / 12 / 71$ & Foguete & Córrego & 75 & 1 & 1,3 \\
$05 / 01 / 72$ & Sto. Angelo & Córrego & 94 & 2 & 2,2 \\
$07 / 01 / 72$ & Sáo Bento & Córrego & 79 & 1 & 1,3 \\
$27 / 06 / 72$ & Olaria Sấo José & Lagoa & 162 & 5 & 3,0 \\
$29 / 06 / 72$ & Bairro São Bento & Várzea & 116 & 1 & 0,9 \\
\hline
\end{tabular}

\subsection{Isolamento da linhagem de} S. mansoni

Com as cercárias de S. mansoni obtidas dos moluscos capturados na represa, infectamos camundongos de laboratório. Após 20 dias da data da infecção, os roedores que morreram apresentavam esquistossômulos nos vasos intra-hepáticos.

Decorridos 60 dias da data da infecção os roedores restantes foram sacrificados encontrando-se granulomas no fígado $\mathrm{e}$ grande número de esquistossomas adultos no plexo Porta. Infectamos exempla- res de B. tenagophila com miracídios obtidos dos granulomas hepáticos.

\subsection{Infecção de camundongos nos focos}

Expusemos Mus musculus albinos em contato direto com as águas. Após dois meses, sacrificados os animais, alguns mostraram-se infectados pelo $S$. Mansoni. Na Tabela 2, transcrevemos os indices de infecção dos camundongos por foco da represa.

Além dos camundongos constantes da 
MAGALHÃES, L. A. et al. - Aspectos epidemiológicos da esquistossomose mansônica na região da Represa de Americana, Estado de Sāo Paulo, Brasil. Rev. Saúde públ., S. Paulo, 7:21-28, 1973.
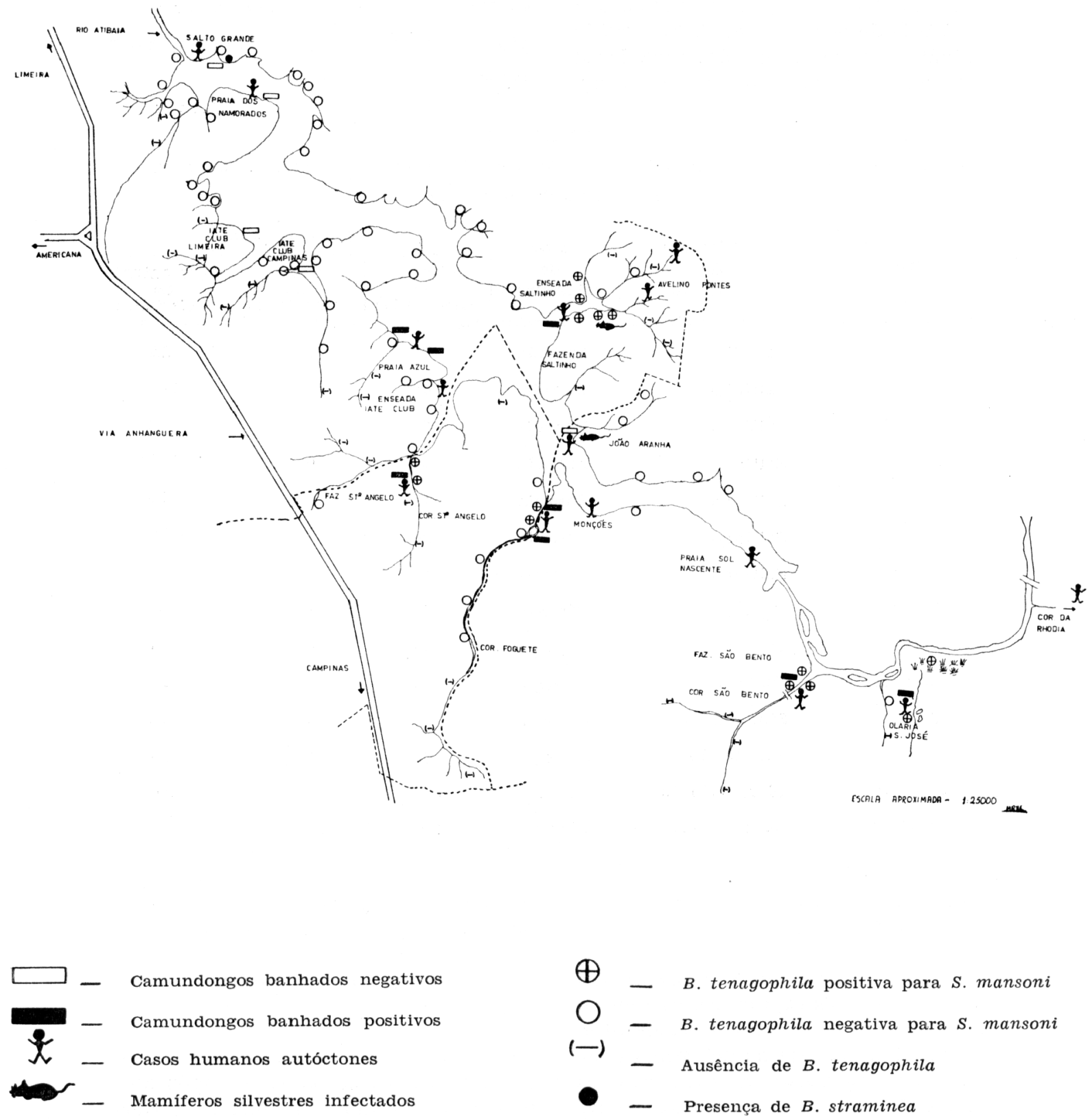

Mapa da Represa de Americana 
MAGALHAES, L. A. et al. - Aspectos epidemlológlcos da esquistossomose mansônica na região da Represa de Americana, Estado de São Paulo, Brasil. Rev. Saúde públ., S. Paulo, 7:21-28, 1973.

Tabela 2 foram expostas outras amostras em diferentes regiões da represa, obtendo-se resultados negativos (vide mapa).

\subsection{Casos humanos autóctones}

A relação dos casos humanos autóctones constam da Tabela 3 (vide mapa).

TABELA 2

fndices de infecção por $S$. mansoni de Mus musculus expostos às águas dos focos na região da Represa de Americuna.

\begin{tabular}{|c|c|c|c|c|}
\hline \multirow[b]{2}{*}{ Data } & \multirow[b]{2}{*}{$\begin{array}{c}\text { Regiāo } \mathbf{d a} \\
\text { represa }\end{array}$} & \multicolumn{3}{|c|}{ Mus musculus } \\
\hline & & $\begin{array}{l}\text { N.O de } \\
\text { roedores } \\
\text { expostos }\end{array}$ & $\begin{array}{c}\text { N. }{ }^{\circ} \text { de } \\
\text { roedores } \\
\text { infectados }\end{array}$ & $\begin{array}{l}\text { Percentual } \\
\text { de roedores } \\
\text { infectados }\end{array}$ \\
\hline $17 / 11 / 71$ & Enseada da Faz. Saltinho & 10 & 6 & 60 \\
\hline $16 / 12 / 71$ & Córrego Foguete & 6 & $\mathbf{5}$ & 83 \\
\hline $16 / 12 / 71$ & Córrego Foguete & 12 & 4 & 33 \\
\hline $21 / 12 / 71$ & Praia Azul & 4 & 3 & 75 \\
\hline $22 / 12 / 71$ & Córrego Foguete & 10 & 9 & 90 \\
\hline $05 / 01 / 72$ & Praia Azul & 12 & 2 & 17 \\
\hline $12 / 01 / 72$ & Córrego Santo Angelo & 12 & 1 & 8 \\
\hline $28 / 02 / 72$ & Praia Azul & 5 & 2 & 40 \\
\hline $22 / 05 / 72$ & Córrego São Bento & 5 & 4 & 80 \\
\hline $29 / 06 / 72$ & Olaria São José & 6 & 1 & 17 \\
\hline
\end{tabular}

TA B ELA 3

Relação de casos autóctones da reglăo da Represa de Americana

\begin{tabular}{l|c}
$\begin{array}{c}\text { Local provável da } \\
\text { contaminação }\end{array}$ & $\begin{array}{c}\text { N.º de } \\
\text { casos }\end{array}$ \\
\hline Praía Azul & 17 \\
Córrego săo Bento & 12 \\
Enseada João Aranha & 10 \\
Monçóes & 8 \\
Enseada Saltinho & 7 \\
Enseada Iate Club & 7 \\
Córrego Santo Angelo & 6 \\
Córrego Foguete & 4 \\
Praia do Sol Nascente & 4 \\
Córrego da Rhodia & 3 \\
Enseada do Salto Grande & 2 \\
Praia dos Namorados & 1 \\
Sitio Avelino Pontes & 1 \\
\hline Total & 82 \\
\hline
\end{tabular}


MAGALHAES, L. A. et al. - Aspectos epidemiológicos da esquistossomose mansônica na regiāo da Represa de Americana, Estado de Săo Paulo, Brasil. Rev. Saúde públ., S. Paulo, 7:21-28, 1973.

\section{DISCUSSAO}

Sugerimos quatro hipóteses que explicariam a manutenção dos focos durante, pelo menos, dois anos, considerando-se como início de atividade o surgimento dos primeiros casos agudos da moléstia.

a) Defecações frequientes de pessoas portadoras de esquistossomose junto aos criadouros de moluscos.

Esta possibilidade é provável devido a presença de acampamentos de turistas nas proximidades de alguns focos.

b) Contaminação oriunda dos moradores residentes próximos aos focos.

Somente em um foco constatou-se a presença de portadores de esquistossomose residentes junto às margens do córrego infectado. Os doentes residiam em casas servidas por fossa negra.

c) O rio Atibaia responsável pela contaminação dos focos.

Recebendo esgotos "in natura" de várias cidades, incluindo-se entre elas Campinas, o rio Atibaia contribui provavelmente como fonte de infecção dos moluscos para três focos. Entretanto, como os focos restantes estão localizados em córregos, ainda que próximos à represa, é pouco provável este mecanismo de infecção.

d) Mamíferos silvestres de pequeno e médio porte, responsáveis pela manutenção dos focos.
Provavelmente estes animais funcionariam como reservatórios naturais de esquistossomose na região, como vem constatando Dias 3 (1972); vários deles são portadores de esquistossomose e eliminam ovos viáveis pelas fezes.

Constatamos que na dispersão dos caramujos infectados é notável o papel dos aguapés, já que observamos nas raízes de Eichornia sp flutuando na parte central da represa, vários exemplares de $B$. tenagophila.

Isto poderia explicar a constatação de casos humanos autóctones em várias regiōes da represa onde não foram encontrados caramujos infectados.

Salientamos o papel que as represas hidroelétricas podem desempenhar na dispersão da esquistossomíase, se não forem tomadas medidas profiláticas. MCCAULL 5 (1969) refere maior incidência da esquistossomose no Egito, após o represamento do rio Nilo.

\section{CON C LUSA O}

A Represa de Americana com seus 90 milhōes de metros cúbicos de água, deve ser considerada como foco de esquistossomose, não só devido às localizações dos focos detetados, como também a constatação de numerosos doentes autóctones, oriundos de várias regiōes da represa. 
MAGALHAES, L. A. et al. - Aspectos epidemiológicos da esquistossomose mansônica na regiáo da Represa de Americana, Estado de São Paulo, Brasil. Rev. Saúde públ., S. Paulo, 7:21-28, 1973.

MAGALHX̃ES, L. A. et al. - [Epidemiological aspects of schistosomiasis mansoni in the Americana reservoir area (S. Paulo, Brazil).]. Rev. Saúde públ., S. Paulo, 7: 21-28, 1973.

Summary: An epidemiological study of the area around the Americana reservoir (S. Paulo, Brazil), following suspicion of several autochthonous human cases of schistosomiasis mansoni, was made. Six active foci were disclosed, the following species of mollusks having been found in the general area: Biomphalaria tenagophila; B. straminea; B. peregrina; Drepanotrema cimex; D. lucidum; Lymnaeidae; Ancylidae and Physidae. Specimens of Biomphalaria tenagophila from the foci revealed indices of infection ranging from 0,9 to 45.0 percent for Schistosoma mansoni cercariae. Laboratory mice infected both in the field and in laboratory, with material from these foci, permitted observation of entire cycle of S. mansoni. Eighty-two autochthonous human cases of schistomiasis mansoni were confirmed in the Americana resorvoir area.

Uniterms: Schistosoma mansoni *; Epidemiology *; Mollusks*; Human infections.

\section{REFERENCIAS BIBLIOGRAFICAS}

1. BRENER, Z. - Contribuiçáo ao estudo da terapêutica experimental da esquistossomose mansônica. Belo Horizonte, 1962. [Tese - Faculdade de Medicina da Universidade de Minas Gerais.]

2. CORReA, R. R. et al. - Dispersáo de Biomphalaria stramínea, hospedeiro intermediário do Schistosoma mansoni através da distribuição de peixes. Rev. Saude públ., S. Paulo, 4: 117-27, 1970 .

3. DIAS, L. C. S. - Small wild mammals naturaly infected with Schistosoma mansoni: preliminar note. Rev. Saúde pübl., S. Paulo, 6:233, 1972.

4. HIIL, J. - Chemoterapeutic studies laratory infections of Schistosoma mansoni. Ann. trop. Med. Parasit., 50:39-48, 1956.

5. McCAULL, J. - Conference on the ecological aspects of international development. Nat. Ress., Paris 2:5-12, 1969.

6. PAN AMERICAN HEALTH ORGANIZATION - A guide for the identificacation of the snail intermediate hosts of schistosomiasis in the Americas. Washington, D.C., 1968.(Sclentific Publication n.o 168).

7. PARAENSE, W. L. - The nomenclature of brazilian planorbids. II. "Australorbis tenagophilus" (Orbigny, 1835). Rev. bras. Biol., $21: 343-9,1961$.

8. PARAENSE, W. L. - The nomenclature of brazilian planorbids. III. "Australorbis straminea" (Dunker, 1848) . Rev. bras. Biol., 23:1-7, 1963.

9. PARAENSE, W. L. \& DESLANDES, D. "Australorbis inflexus". SP.N. from Brazil (Pulmonata, Planorbidea). Rev. bras. Biol., 16:149-58, 1956.

10. Paraense, W. L. \& Deslandes, D. The brazilian species of "Drepanotrema". II. "D. melleum" (Lutz, 1918). Rev. bras. Biol., 16:527-34, 1956.

11. PaRAense, W. I. \& DESLANDES, D. The brazilian specles of "Drepanotrema". IV " $D$. cimex" (Moricand, 1837). Rev. bras. Biol., 18:187-92, 1958.

12. PELLEGRINO, J. \& MACHDO, D. G. A simplified method for the con- 
MAGalhaES, L. A et. al. - Aspectos epidemiológicos da esquistossomose mansônica na região da Represa de Americana. Estado de Sâo Paulo, Brasil. Rev. Saúde públ., S. Paulo, 7:21-28, 1973.

centration of cercariae. J. Parasit., 41:329-30, 1955 .

13. PELlegrino, J. \& MACEDo, D. G. Novo critério de leitura da reação intradérmica na esquistossomose. Rev. bras. Malar., 8:499-509, 1956.

14. STANDEN, $O$. D. - The relationship of sex in Schistosoma mansoni to migration within the hepatic port sys- tem of experimentally infected mice. Ann. trop. Med. Parasit., $47: 139-45$, 1953 .

15. YOLLES, T.K. et al. -- A technique for the perfusion of laboratory animals for the recovery of schistosomes. $J$. Parasit., 33:419-26, 1947.

Recebido para publicação em 16-11-1972

Aprovado para publicação em 29-1-1973 